\title{
TRATAMENTO DE ÁGUAS RESIDUÁRIAS DE FECULARIA POR MEIO DE LAGOAS DE ESTABILIZAÇÃO
}

\author{
ALESSANDRO T. CAMPOS ${ }^{1}$, JACIR DAGA ${ }^{2}$, EMANUEL E. RODRIGUES ${ }^{2}$, GILMAR \\ FRANZENER ${ }^{2}$, MARY M. T. SUGUIY ${ }^{2}$, VERA L. G. SYPERRECK ${ }^{2}$
}

\begin{abstract}
RESUMO: Embora o uso de lagoas de tratamento seja uma tecnologia amplamente conhecida e utilizada para resíduos orgânicos, no caso específico dos resíduos líquidos da industrialização da mandioca, as experiências são reduzidas. Assim, o objetivo deste trabalho foi de avaliar a eficiência na redução da carga poluidora de lagoas de tratamento de resíduos líquidos de fecularia. Para tanto, foram coletadas amostras na entrada do sistema e em cada uma das sete lagoas da Fecularia Horizonte, em Marechal Cândido Rondon - PR, no período de maio a setembro de 2004. Os seguintes parâmetros foram avaliados: Demanda Bioquímica de Oxigênio (DBO), Demanda Química de Oxigênio (DQO), Sólidos Totais (ST), Sólidos Fixos (SF), Sólidos Voláteis (SV), N-NH${ }_{4}^{+}$, Condutividade Elétrica (CE), Fósforo (P), Cloretos (CL') e pH. O sistema promoveu redução de 96,3\% de DQO e 96,4\% de DBO, e fósforo e sólidos apresentaram comportamento semelhante. Já $\mathrm{N}-\mathrm{NH}_{4}{ }^{+}, \mathrm{CL}^{-}$e CE oscilaram durante o sistema com redução, sobretudo nas lagoas de polimento.
\end{abstract}

PALAVRAS-CHAVE: manipueira, efluente, mandioca.

\section{RESIDUARY WATER TREATMENT OF FECULARIA BY MEANS OF STABILIZATION LAGOONS}

ABSTRACT: The use of lagoon of treatment is a technology thoroughly known and used for organic residues. But, in the specific case of liquid residues from the cassava industrialization, the experiences are reduced. The objective of this study was evaluating the efficiency in the reduction of the pollutant load of lagoons of treatment of liquid residues of cassava industry. Thus samples were collected in the entrance of the system and in each of the seven lagoons of the Fecularia Horizonte, in Marechal Cândido Rondon - PR, Brazil, from May to September of 2004. The following parameters were appraised: Biochemical Oxygen Demand (BOD), Chemical Oxygen Demand (COD), Total Solids (TS), Fixed Solids (FS), Volatile Solids (VS), N-NH + 4, Electric Conductivity (EC), Phosphorus (P), Clorets $\left(\mathrm{Cl}^{-}\right)$and $\mathrm{pH}$. The system promoted reduction of $96.3 \%$ of $\mathrm{COD}$ and $96.4 \%$ of BOD, and phosphorus and solids presented similar behavior. However, $\mathrm{N}-\mathrm{NH}^{+}{ }_{4}, \mathrm{CL}^{-}$and $\mathrm{EC}$ oscillated during the system with reduction, mainly in the polishing ponds.

KEYWORDS: manipueira, effluent, cassava.

\section{INTRODUÇÃO}

Nos processos de industrialização da mandioca, para fins de obtenção de farinha ou fécula, são gerados resíduos sólidos de descarte, partes lenhosas e deterioradas das raízes, crueira, porções fibrosas retidas em peneiras, bagaços e resíduos líquidos da água de lavagem das raízes e manipueira (FERNANDES JÚNIOR \& CEREDA, 1996). Dentre esses, destaca-se a manipueira líquida resultante da prensagem da massa ralada utilizada para a produção de farinha e do processo de extração e purificação da fécula (TAKAHASHI, 1987).

\footnotetext{
${ }^{1}$ Prof. Dr., Instituto de Ciências Agrárias, UFVJM, Diamantina - MG, Fone: (0XX38) 3531.1811, atcampos3@ yahoo.com.br.

${ }^{2}$ Mestrandos, UNIOESTE, Marechal Cândido Rondon - PR.

Recebido pelo Conselho Editorial em: 17-12-2004

Aprovado pelo Conselho Editorial em: 16-11-2005 
A manipueira é o resíduo mais problemático por possuir elevada carga de poluente e efeito tóxico, devido ao glicosídeo cianogênico linamarina, causando sérios problemas ao ambiente quando lançado em cursos d'água (BARANA \& CEREDA, 2000). Esse problema agrava-se em virtude de a concentração das indústrias estar na região Sul do País e Mato Grosso do Sul (LEONEL \& CEREDA, 1998).

O Paraná, particularmente a região oeste, tem enfrentado problemas ambientais devido à concentração dessas indústrias e dos resíduos por elas gerados. Esses se caracterizam por apresentar carga orgânica de Carbono Orgânico Total (COT) em torno de $2.604 \mathrm{mg} \mathrm{L}^{-1}$, Demanda Bioquímica de Oxigênio (DBO) de $11.484 \mathrm{mg} \mathrm{L}^{-1}$ e pH de 6,18 (FEIDEN \& CEREDA, 2003).

Em relação às outras águas residuárias, estima-se o uso de cerca de 15 a 40 milhões de metros cúbicos de água para lavagem das raízes, produzindo aproximadamente 40 mil toneladas de DBO, sendo equivalente à carga poluidora diária de uma cidade de 2 milhões de habitantes (BIANCHI \& CEREDA, 1999).

A quantidade e a qualidade dos resíduos gerados no processo de extração de amido de mandioca variam devido a vários fatores, como idade do tubérculo, tempo de armazenamento e tipo do processo utilizado (TORRES et al., 2003).

A literatura mundial relata inúmeros processos de tratamento e/ou aproveitamento de resíduos orgânicos, destacando os processos biológicos, sejam os aeróbios (lodo ativado, lagoas de estabilização aeróbia, etc.), sejam os anaeróbios (biodigestores, lagoas de estabilização anaeróbia, etc.) para o tratamento de efluente (FERNANDES JÚNIOR, 2001).

Segundo PARIZOTTO (2002), a sazonalidade do processamento das raízes torna os prétratamentos dos efluentes de difícil consecução e de reduzida eficácia, pois, em determinado período do ano, a indústria pára de trabalhar por falta de raízes, utilizando-se de lagoas de sedimentação como forma de simplificar a composição dos sistemas de tratamentos, diminuindo o consumo de produtos neutralizantes, de energia elétrica e eliminando a necessidade de adição de nutrientes.

Em lagoas de estabilização no oeste do Paraná, atualmente, são utilizados equipamentos mecânicos, exceto em casos que se deseja aceleração do processo de depuração, quando se utilizam aeradores (BERNI \& BAJAY, 2000), obtendo destaque entre os processos de baixo custo (KOETZ et al., 1995).

Dentre as diversas tecnologias de tratamento de efluentes, o sistema de lagoas de estabilização foi o que se adaptou melhor às condições do oeste do Paraná, apesar de inúmeras dificuldades enfrentadas nas fases iniciais de implantação. Embora o sistema de lagoas represente uma solução de fato para o tratamento de efluentes provenientes de fecularias, a experiência é pequena e necessita ser ampliada, sendo necessárias pesquisas sistemáticas para possibilitar a melhoria do manejo (FEIDEN, 2001; PARIZOTTO, 1999).

O tratamento das águas residuárias geradas em fecularias, utilizando-se de lagoas de estabilização em série, além de ser um processo simples, tende a mostrar-se eficiente, sobretudo reduzindo a carga orgânica, uma vez que cada lagoa apresenta características e funções distintas.

Assim, o objetivo deste trabalho foi de avaliar a eficiência na remoção da carga poluidora e de diferentes parâmetros de qualidade de um sistema de tratamento de águas residuárias geradas em fecularias por lagoas de estabilização.

\section{MATERIAL E MÉTODOS}

Este trabalho foi desenvolvido na Fecularia Horizonte, localizada em Novo Três Passos, Distrito de Marechal Cândido Rondon, Paraná. 


\section{Sistema de tratamento}

O tratamento dos efluentes da indústria foi realizado por uma seqüência de sete lagoas de estabilização, cuja distribuição e dimensões estão apresentadas na Figura 1. A primeira lagoa a receber o resíduo é anaeróbia (lagoa 01), apresentando área de $2.318 \mathrm{~m}^{2}$ e profundidade de $5 \mathrm{~m}$. Dessa, o efluente é bombeado para outra lagoa anaeróbia (lagoa 02) com área de $3.162 \mathrm{~m}^{2}$ e $5 \mathrm{~m}$ de profundidade, da qual o efluente escoa por gravidade para uma terceira lagoa anaeróbia (lagoa 03) de $2.382 \mathrm{~m}^{2}$ e $5 \mathrm{~m}$ de profundidade, seguida de duas lagoas facultativas. A primeira (lagoa 04) possui área $3.961 \mathrm{~m}^{2}$ e a segunda (lagoa 05) $3.108 \mathrm{~m}^{2}$, sendo ambas com profundidade de $4 \mathrm{~m}$. Por final, o efluente passa por duas lagoas facultativas, sendo a primeira (lagoa 06) com área de $2.433 \mathrm{~m}^{2}$ e $2 \mathrm{~m}$ de profundidade, e a outra (lagoa 07) apresenta área de $1.776 \mathrm{~m}^{2}$ e também $2 \mathrm{~m}$ de profundidade, sendo o efluente despejado em um rio.

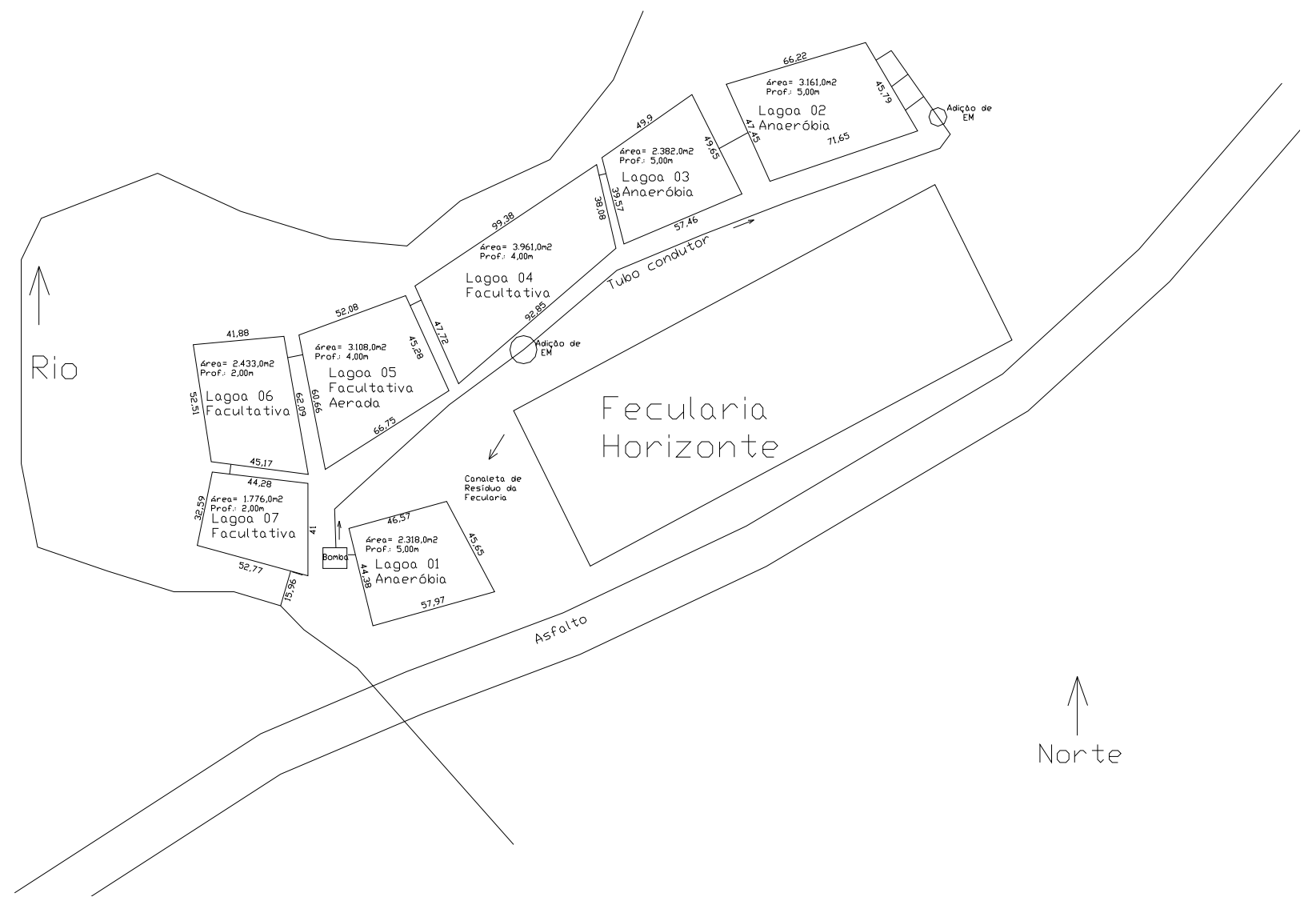

FIGURA 1. Croqui do sistema de tratamento da Fecularia Horizonte.

O tempo de detenção da água residuária no sistema é de aproximadamente 30 dias. Quanto ao emprego de aeradores, apenas a lagoa 05 dispõe desse dispositivo.

Com o objetivo de aumentar a eficiência do sistema, em dois pontos da tubulação de bombeamento, são adicionados microrganismos adaptados ao tratamento de águas residuárias de fecularia, os quais são fornecidos pela Fundação Mokiti Okada de Ipeúna - SP.

\section{Coleta das amostras e análises}

Foram coletadas, mensalmente, amostras na entrada do sistema e em cada uma das sete lagoas, no período de maio a setembro de 2004, totalizando cinco pequenas amostragens. Os seguintes parâmetros foram avaliados: Demanda Bioquímica de Oxigênio (DBO), Demanda Química de 
Oxigênio (DQO), Sólidos Totais (ST), Sólidos Fixos (SF), Sólidos Voláteis (SV), N-NH${ }_{4}^{+}$, Condutividade Elétrica (CE), Fósforo (P), Cloretos $\left(\mathrm{Cl}^{-}\right)$e pH.

As análises físicas, químicas e bioquímicas foram realizadas, conforme metodologia descrita no STANDARD METHODS FOR THE EXAMINATION OF WATER AND WASTEWATER (APHA, 1992), pela Fundação Mokiti Okada MOA, em Ipeúna - SP.

\section{RESULTADOS E DISCUSSÃO}

Os valores de DQO e DBO, quantificados nas amostras coletadas nas lagoas, estão apresentados na Figura 2. Observa-se que o sistema de tratamento recebe elevada carga orgânica, não diferindo muito da literatura para tais efluentes. Segundo SILVA et al. (2003 a), o fato de a DQO ser mais elevada que a DBO se deve em virtude da maior facilidade com que grande número de compostos pode ser oxidado por via química do que por via biológica. Na lagoa 01 (anaeróbia), observou-se redução tanto na DQO como na DBO. FEIDEN (2001) e PARIZOTTO (1999) citam que, em sistemas de decantação, a remoção de DBO não é maior que 30\%, embora, segundo TORRES et al. (2003), a atividade microbiana nessa lagoa é prejudicada por vários fatores, como elevados teores de cianuretos. Nas lagoas 02 e 03 (anaeróbias), observa-se maior redução, tanto de DBO como, e principalmente, de DQO.
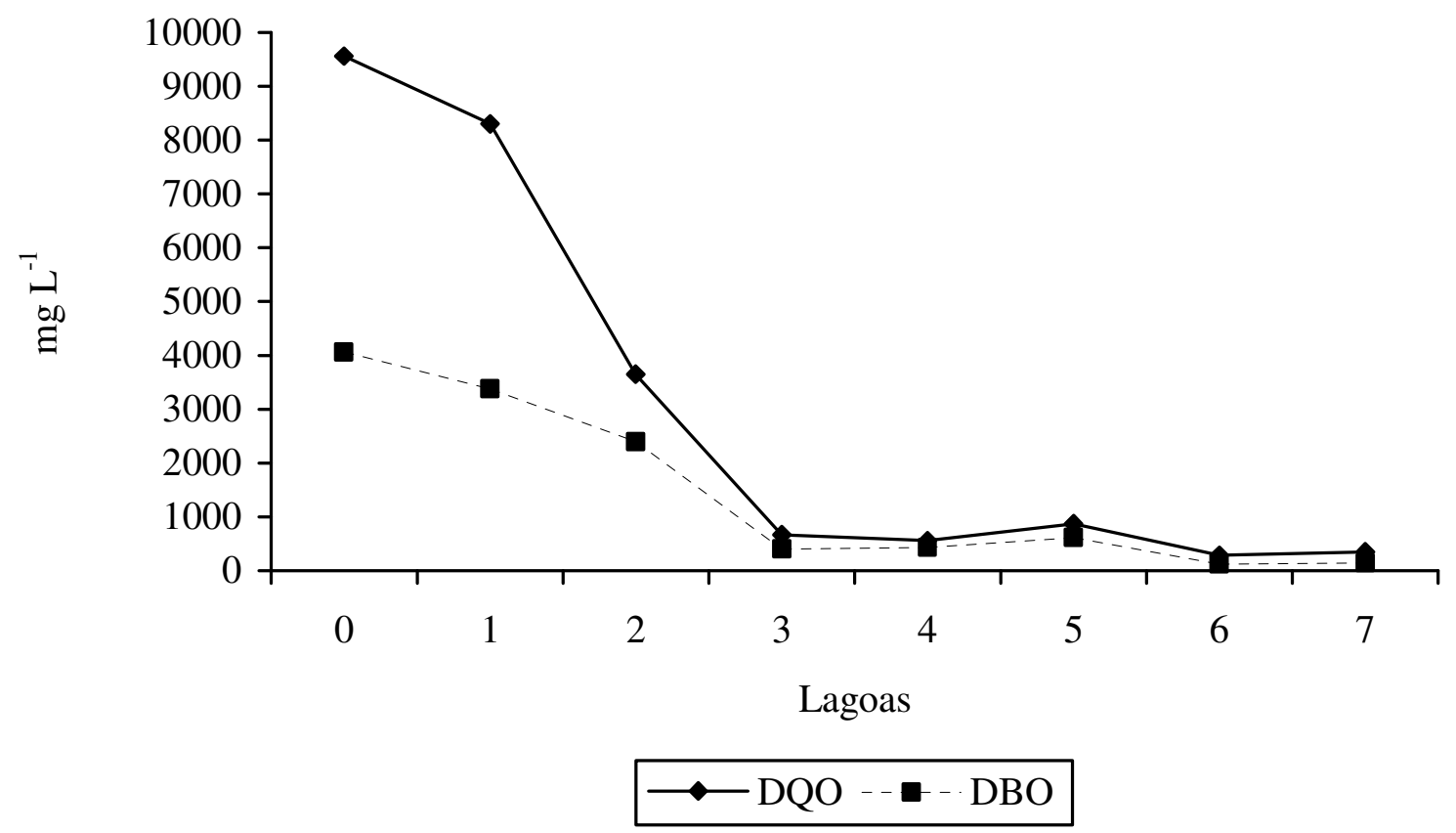

FIGURA 2. Valores médios de DQO e DBO $\left(\mathrm{mg} \mathrm{L}^{-1}\right)$ da água residuária bruta e no efluente das sete lagoas do sistema de tratamento de resíduos líquidos da Fecularia Horizonte.

O sistema de tratamento promoveu redução de aproximadamente $96,3 \%$ de DQO e $96,4 \%$ de DBO. Segundo PARIZOTTO (2002), a eficiência de remoção da carga orgânica bruta no sistema de tratamento convencional situa-se, em média, na faixa de $70 \%$, enquanto a eficiência no sistema de tratamento simplificado (com lagoa de sedimentação) pode chegar a mais de 95\%, conferindo com os resultados obtidos neste trabalho.

Embora o sistema tenha se mostrado eficiente na remoção da carga orgânica, os valores de DQO e DBO ainda são muito elevados ao final do sistema. Porém, alguns fatores devem ser considerados, como o fato de a sazonalidade de funcionamento das indústrias ser concentrada nos meses de abril a agosto (PARIZOTTO, 1999) (período da coleta da maioria das amostras), culminando com maior 
produção de resíduos e, portanto, menor tempo de residência nas lagoas. Além disso, esse período coincide com temperaturas mais amenas que diminuem a atividade microbiana das lagoas.

Quanto às lagoas de polimento, segundo MASCARENHAS et al. (2004), no tratamento de esgotos, o objetivo principal dessas lagoas deixa de ser a estabilização da matéria orgânica e passa a ser a remoção de patógenos, porém essas podem promover importante remoção adicional da carga orgânica, contribuindo para a eficiência global do sistema.

O fósforo, analogamente ao nitrogênio, é um nutriente muito importante para o crescimento e reprodução de microrganismos que promovem a estabilização da matéria orgânica, porém o efluente rico em fósforo pode provocar proliferação excessiva de algas no curso d'água receptor (SILVA et al., 2003b).

Valores de $\mathrm{pH}$ e fósforo total estão apresentados na Figura 3. Fósforo total apresentou comportamento semelhante ao da DQO e da DBO, porém com grande redução (pela oxidação) dos valores já na lagoa 01 (anaeróbia) e com redução média ao final do sistema de 93,5\%. PARIZOTTO (1999) observou remoção de fosfato superior a $60 \%$ e cita que as eficiências de remoção do fosfato alcançadas nessas lagoas denotam que a biomassa presente no interior dessas lagoas assimila apreciáveis quantidades do nutriente e seus derivados presentes nos despejos via oxidação dos compostos orgânicos. Isso explica a queda do fósforo, como mostra a Figura 3, da entrada 0 até a lagoa 01 .

Conforme esperado, o pH tendeu a aumentar durante a seqüência de lagoas. Segundo ANNE \& FIDALGO (2000), isso ocorre devido à maior presença de algas nas lagoas que utilizam ativamente os nutrientes e produzem oxigênio, levando ao aumento do $\mathrm{pH}$. Segundo os mesmos autores, valores elevados de $\mathrm{pH}$ provocam precipitação dos fosfatos, o que ajuda a explicar a redução nos teores de fósforo durante o sistema. FEIDEN (2001) cita que maiores valores de $\mathrm{pH}$ tendem a ocorrer nas lagoas de polimento (ou maturação), uma vez que são mais rasas e assim a radiação solar penetra em praticamente toda a massa de água, ocorrendo elevada concentração de oxigênio dissolvido resultante da fotossíntese.

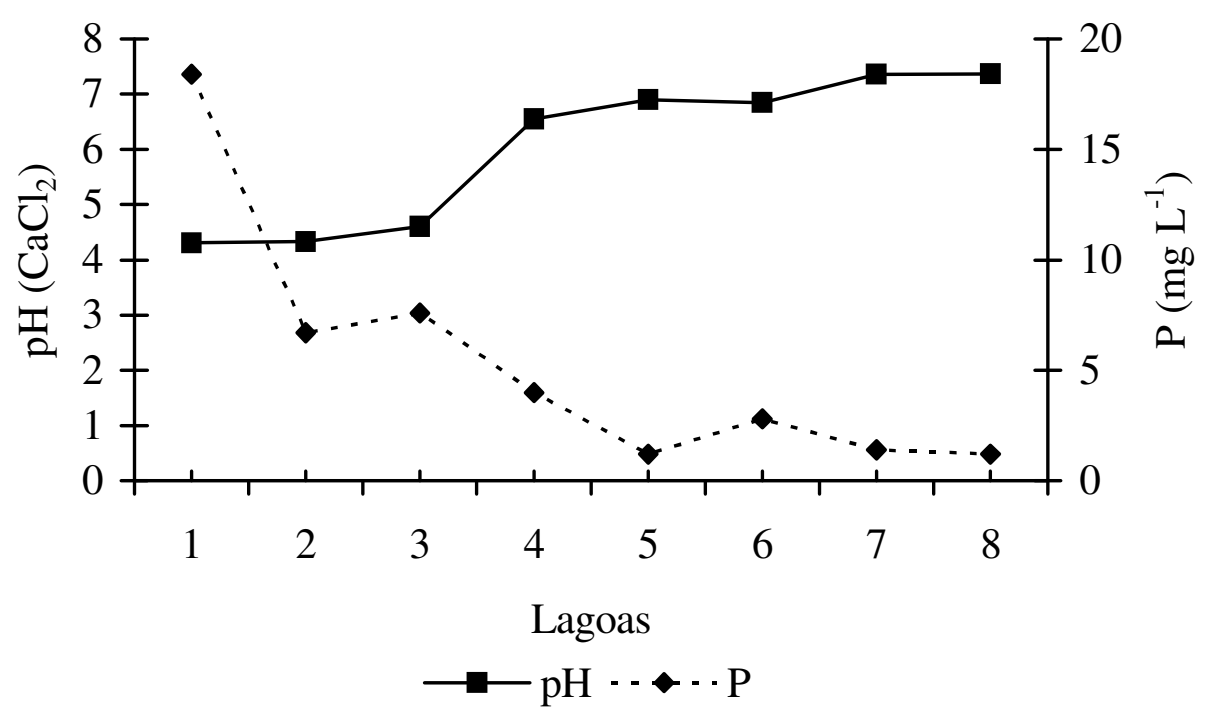

FIGURA 3. Valores médios de $\mathrm{pH}\left(\mathrm{CaCl}_{2}\right.$, adimensional) e fósforo $\left(\mathrm{mg} \mathrm{L}^{-1}\right)$ da água residuária bruta e no efluente, nas sete lagoas do sistema de tratamento de resíduos líquidos da Fecularia Horizonte. 
Os valores de $\mathrm{NH}_{4}^{+}$não apresentaram elevada variação no sistema (Figura 4). Observou-se sensível aumento na parte intermediária do sistema e redução na última lagoa (facultativa). Para MASCARENHAS et al. (2004), os valores de amônio podem aumentar como resultado do processo de amonificação, que consiste na conversão, por meio de ação de bactérias heterotróficas, da matéria nitrogenada orgânica, que se encontra na forma solúvel, em amônia. Por outro lado, segundo os mesmos autores, o mecanismo de remoção do amônio e transformação em amônia é dependente da temperatura, sendo que o aumento da mesma conduz à elevação da fração não ionizada $\left(\mathrm{NH}_{3}\right)$ da amônia e à diminuição da fração ionizada $\left(\mathrm{NH}^{+}{ }_{4}\right)$. Portanto, como neste trabalho as coletas foram realizadas em período de temperaturas mais amenas, provavelmente esse fator tenha contribuído para baixa remoção de $\mathrm{NH}_{4}^{+}$.

Os valores de cloretos e condutividade elétrica oscilaram entre as lagoas, havendo sensível redução na lagoa 04, tornando a aumentar na lagoa 05, pela atividade do aerador, porém as últimas lagoas facultativas foram eficientes para diminuir tais valores. Essa elevação dos valores de cloretos e condutividade elétrica provavelmente é contribuída pela atividade do aerador (em funcionamento), que auxilia a difusão de sais minerais na massa líquida, originários da degradação de partículas coloidais precipitadas (FEIDEN, 2001).
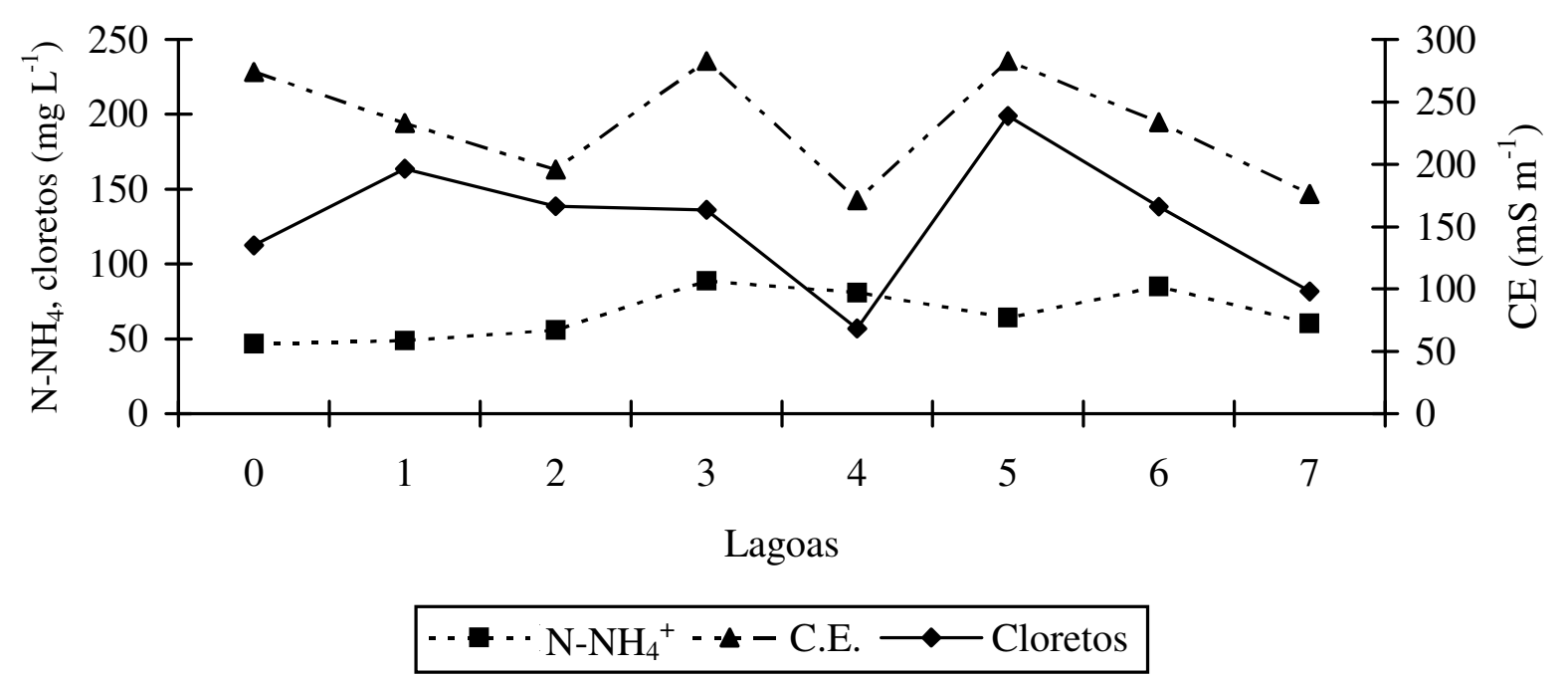

FIGURA 4. Valores médios de $\mathrm{N}-\mathrm{NH}_{4}{ }^{+}$, cloretos $\left(\mathrm{mg} \mathrm{L}^{-1}\right)$ e condutividade elétrica $(\mathrm{mS} / \mathrm{m})$ da água residuária bruta e no efluente, nas sete lagoas do sistema de tratamento de resíduos líquidos da Fecularia Horizonte.

Na Figura 5, estão apresentados os valores de Sólidos Totais (ST), Sólidos Fixos (SF) e Sólidos Voláteis (SV). Pode-se observar que ST, SF e SV apresentaram comportamento semelhante entre si nas diferentes lagoas do sistema de tratamento. Esse promoveu a redução de 67,0\%; 58,3\% e 72,3\% para ST, SF e SV, respectivamente. Já PARIZOTTO (1999), trabalhando com lagoas de sedimentação, obteve, nessas lagoas, eficiência média de remoção de sólidos totais em torno de $80 \%$. Em comparação com os outros parâmetros estudados, ST, SF e SV apresentaram comportamento semelhante ao de concentração de fósforo, à $\mathrm{DQO}$ e à $\mathrm{DBO}$, havendo tendência de redução dos valores durante o sistema de tratamento. 


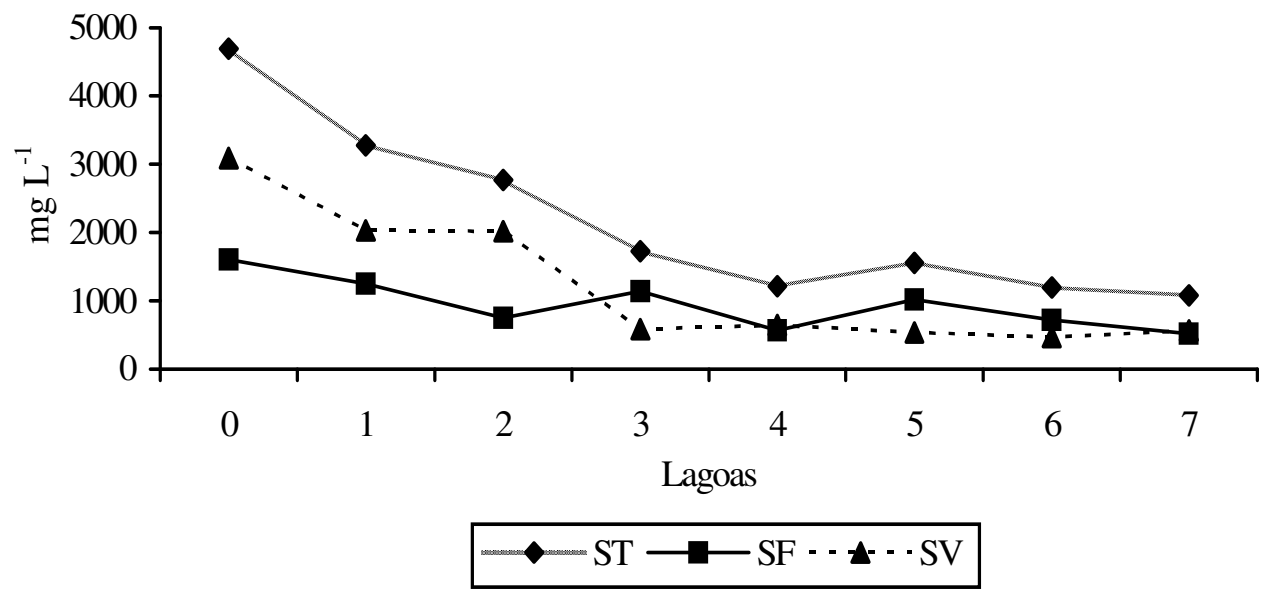

FIGURA 5. Valores médios de sólidos totais (ST), sólidos fixos (SF) e sólidos voláteis (SV) (mg L $\mathrm{L}^{-1}$ ) da água residuária bruta e no efluente, nas sete lagoas do sistema de tratamento de resíduos líquidos da Fecularia Horizonte.

\section{CONCLUSÕES}

As águas residuárias de fecularia apresentam elevada carga poluidora, principalmente elevadas concentrações de DQO e DBO.

As lagoas anaeróbias foram as que promoveram a maior redução nos valores de DQO e DBO, mostrando elevada conversão de matéria orgânica em produtos finais.

As lagoas facultativas apresentaram redução adicional de carga poluidora, contribuindo para maior eficiência total do sistema.

O sistema de lagoas de estabilização em série é eficiente para a redução da carga poluidora da água residuária de fecularia.

\section{REFERÊNCIAS}

AMERICAN PUBLIC HEALTH ASSOCIATION - APHA. Standard methods for the examination of water and wastewater. $18^{\text {th }}$ ed. Washington, 1992. $1.219 \mathrm{p}$.

ANNE, I.; FIDALGO, M.L. Diferenciação do funcionamento de dois ecossistemas aquáticos através do uso da análise dos componentes principais. In: CONGRESSO IBÉRICO SOBRE

PLANEJAMENTO E GESTÃo DA ÁGUA, Porto, 2000. Disponível em:

<http://www.us.es/ciberico/archivos_html/oportotema1.1.htm>. Acesso em: 7 out. 2004.

BARANA, A.C.; CEREDA, M.P. Cassava wastewater manipueira treatment using a two-phase anaerobic biodigestor. Ciência e Tecnologia de Alimentos, Campinas, v.20, n.2, p.183-6, 2000.

BERNI, M.D.; BAJAY, S.V. Geração de energia e a digestão anaeróbia no tratamento de efluentes: estudo-de-caso na indústria de papel. In: ENCONTRO DE ENERGIA NO MEIO RURAL, 3., 2000, Campinas. Anais... Campinas: UNICAMP, 2000. 1 CD-ROM.

BIANCHI, V.L.; CEREDA, M.P. Balanço de massa de uma fábrica de mandioca de médio porte do estado de São Paulo. Energia na Agricultura, Botucatu, v.14, n.3, p.34-48, 1999. 
FEIDEN, A. Avaliação da eficiência de lagoas de tratamento de resíduos líquidos. In: CEREDA, M.P. (Coord.) Manejo, uso e tratamento de subprodutos da industrialização da mandioca. São Paulo: Fundação Cargill, 2001. v.4, cap.13, p.186-201.

FEIDEN, A.; CEREDA, M.P. Potencial energético do biogás gerado no tratamento de águas residuárias de fecularias em sistema piloto de biodigestão anaeróbia com separação de fases. Energia na Agricultura, Botucatu, v.18, n.2, p.54-66, 2003.

FERNANDES JÚNIOR, A. Tratamentos físicos e biológicos da manipueira. In: CEREDA, M.P. (Coord.) Manejo, uso e tratamento de subprodutos da industrialização da mandioca. São Paulo: Fundação Cargill, 2001. v.4, cap.10, p.138-50.

FERNANDES JÚNIOR, A.; CEREDA, M.P. Influência do tempo de retenção hidráulica (TRH) sobre a fase acidogênica da digestão anaeróbia de manipueira. Energia na Agricultura, Botucatu, v.11, n.3, p.1-7, 1996.

KOETZ, P.R.; FARIA, O.L.V.; NUNES, W.A. Tratamento de efluentes homogeneizados de curtume por digestão anaeróbia em reatores de fluxo ascendente. Revista Brasileira de Agrociência, Pelotas, v.1, n.1, p.23-9, 1995.

LEONEL, M.; CEREDA, M.P. Avaliação técnico-econômica da produção de etanol de farelo de mandioca, utilizando pectinase como enzima complementar. Energia na Agricultura, Botucatu, v.13, n.2, p.1-14, 1998.

MASCARENHAS, L.C.A; SPERLING, M. Von; CHERNICHARO, C.AL. Avaliação do desempenho de lagoas de polimento rasas, em série, para o pós-tratamento de efluentes de reator UASB.

Engenharia Sanitária e Ambiental, Rio de Janeiro, v.9, n.1, p.45-54, 2004.

PARIZOTTO, A.A. Eficiência de lagoas de sedimentação na remoção de cargas orgânicas, nutrientes e coliformes totais em despejos industriais de fecularias. 1999. 113 f. Dissertação (Mestrado em Recursos Hídricos e Meio Ambiente) - Universidade Estadual do Oeste do Paraná, Cascavel, 1999.

PARIZOTTO, A.A. Minimização de custos econômicos e ambientais pelo uso de lagoas de sedimentação no tratamento de despejos de fecularias. Informe Gepec, Toledo, v.6, n.2, p.7-16, 2002.

SILVA, F.F.; FREITAS, P.S.L.; BERTONHA, A.; REZENDE, R.; GONÇALVES, A.C.A.;

DALLACORT, R. Variação a carga orgânica do efluente de fecularia de mandioca. Acta Scientiarum, Maringá, v.25, n.1, p.161-5, 2003 a.

SILVA, F.F.; FREITAS, P.S.L.; BERTONHA, A.; REZENDE, R.; GONÇALVES, A.C.A.; DALLACORT, R.; Flutuações das características químicas do efluente industrial de fecularia de mandioca. Acta Scientiarum, Maringá, v.25, n.1, p.167-75, 2003 b.

TAKAHASHI, M. Aproveitamento da manipueira e de resíduos do processamento da mandioca. Informe Agropecuário, Belo Horizonte, v.13, n.145, p.83-7, 1987.

TORRES, P.; RODRÍGUES, J.A.; URIBE, I.E. Tratamiento de águas residuales del proceso de extracción de almidón de yuca en filtro anaerobio: influencia del medio de soporte. Scientia et Technica, Pereira - Colombia, v.29, n.23, p.75-80, 2003. 